\title{
A cohort mortality study and a case-control study of workers potentially exposed to styrene in the reinforced plastics and composites industry
}

\author{
Otto Wong
}

\begin{abstract}
The cohort consisted of 15908 men and women who worked for at least six months between 1948 and 1977 in 30 participating manufacturing plants in the reinforced plastics and composites industry. These workers were occupationally exposed to the working environment in the industry, which included exposure to styrene. Cause specific mortality analyses were performed based on the standardised mortality ratio (SMR) with the United States population as a comparison. No significant excess of cause specific mortality was found for the total cohort. Mortality from cancer was slightly less than expected (SMR = $88 \cdot 1)$. For cancer of the respiratory system, a small non-significant excess was detected $(\mathrm{SMR}=116 \cdot 1)$. For lymphatic and haematopoietic cancer, a non-significant deficit was found $(S M R=73 \cdot 3)$. The observed mortality from leukaemia was similar to that expected (five observed $v \mathbf{4} \cdot 76$ expected deaths). The plants with hot processes (injection moulding, centrifugal casting, compression moulding, continuous lamination, and pultrusion) experienced a significantly increased SMR (177.9) for respiratory cancer, which was more than twice that $(\mathbf{7 8 \cdot 3 )}$ for those with cold processes (resin mixing, lay up and spray up, bag moulding, and filament winding). As potential exposure to styrene from hot processes is considerably less than that from the cold processes, this finding could not be attributed to occupational exposures. A subsequent nested case-control study consisting of $\mathbf{4 0}$ cases of deaths from respiratory cancer was conducted. Further information on detailed work history, occupational exposures, and smoking history was collected. The case-control study did not show any significant association between respiratory cancer and direct exposure to styrene (contained in polyester resins), dura-
\end{abstract}

ENSR Health Sciences, 1320 Harbor Bay Parkway, Alameda, CA 94501, USA

O Wong tion of exposure to styrene, the type of process (hot or cold), or whether a resin was used. A statistically significant association (relative risk $=7 \cdot 33$ ) was found between cigarette smoking and respiratory cancer among the study subjects.

Styrene is a widely used chemical, mostly in making synthetic rubber, resins, polyesters, plastics, and insulators. A number of epidemiological investigations have been conducted to assess the potential carcinogenicity of styrene. Some of them suggested that workers exposed to styrene might be at a higher risk of developing lymphatic and haematopoietic cancers, including leukaemia ${ }^{123}$ and lymphoma. ${ }^{145}$ Other epidemiological studies did not find such excesses. ${ }^{6-9}$ For example, the largest study consisting of 13920 styrene butadiene rubber workers did not find any cancer excess, ${ }^{9}$ and another large scale investigation based on 7949 glass reinforced plastics workers with exposure to styrene actually reported a deficit in lymphatic and haematopoietic cancer. ${ }^{8}$ Interpretation of epidemiological studies of workers exposed to styrene is difficult because of small sample size and concomitant exposures (for example, to benzene) in some investigations. More epidemiological data on styrene is, however, desirable.

This report summarises an epidemiological investigation of mortality experience of workers in the reinforced plastics and composites industry, who were potentially exposed to styrene monomer. The investigation consisted of three separate phases; a feasibility assessment, a historical prospective cohort study, and a case-control study of respiratory cancer.

\section{Materials and methods}

A feasibility assessment was made to determine whether a mortality study could be done and to provide information for development of protocol. Based on this, 30 reinforced plastics manufacturing plants were selected for the mortality study. Selection criteria included extent of potential exposure to styrene, number of workers exposed, completeness of employment records, earliest date of record availability, and possible duration of latency. 
The cohort consisted of those who worked in an area or areas with potential exposure to styrene for at least six months between 1 January 1948 and 31 December 1977 at any of the 30 selected reinforced plastics manufacturing plants. Those employees who worked in the production areas, the maintenance departments, and the receiving, shipping, and warehousing departments were considered to be potentially exposed to styrene, and were eligible for cohort membership. Office employees, with no previous production experience, were not included.

The cohort was constructed by using employment records available at each plant. The records varied greatly from plant to plant, but generally included the following information; name, social security number, sex, date of birth, date of leaving if appropriate, and summary of work history.

Deaths among active employees and annuitants were identified through company records. Vital state of employees who had left was determined through social security administration records. This was supplemented by local follow up, which included inquiries to plant personnel. For all cohort members who died during the observation period death certificates were requested from appropriate state vital statistics departments. The causes of death were coded according to the 7th revision of the International Classification of Diseases.

It was necessary to develop a method for grouping jobs from different plants with similar potential for exposure to styrene. Because of the lack of reliable data on industrial hygiene in the industry, Arthur D Little Inc (ADL), a consulting firm, was contracted independently to collect data on exposure. ${ }^{10}$

A record job title list (RJT) was generated based on personnel records. The initial list was then consolidated to eliminate duplications. The consolidated RJT (by plant) was provided to ADL for the survey of industrial hygiene and classification of exposure. The ADL industrial hygiene survey included current or past time weighted average (TWA) values (ppm) and peak range exposure values (ppm). Similar RJTs were consolidated into study job titles (SJTs), if their TWAs fell within a common $10 \mathrm{ppm}$ increment $(0-9,10-19,20-29$, etc.) and they had identical peak range values. ${ }^{10}$ These data were incorporated into a job dictionary with some 4000 RJTs grouped into $173 \mathrm{SJTs}$. This information was utilised to group cohort members into exposure categories.

The basic unit of statistical computation was the number of years each employee was followed up after six months of employment or 1 January 1948 (whichever was later), to the end of the study period or the date of death (whichever was earlier). For those "lost to follow up," person-years of observation were counted up to the last date of contact, which was usually the termination date. Each year (or fraction thereof) contributed by a particular worker was classified by age, sex, and calendar year, and the person-years of all workers were then summed up by age, sex, and calendar year. The United States national age-cause-race-specific death rates for five year periods from 1948 to 1977 were applied to these person-years to obtain the number of deaths from a particular cause to be expected from an equal number of person-years of the same sex and similar in age and calendar year. Standardised mortality ratios (SMRs) were computed by expressing the observed deaths as percentages of the expected. The actual computation was performed using a standard computer program. ${ }^{11}$

\section{Results of the cohort study}

Included in the cohort were 15908 employees from 30 plants; $12028(75.6 \%)$ men and $3880(24.4 \%)$ women. From the employment records, race information was available for 3658 workers $(23.0 \%$ of the total cohort). Among these 3658 workers with known race, only $46(1.3 \%)$ were non-white. For the purpose of analysis, the entire cohort was assumed to be white.

Almost half of the cohort (46.0\%) had worked for less than two years at the participating plants. About a third $(31.9 \%)$ had worked for two to five years. Only $22 \cdot 1 \%$ had worked for five years or more.

At the end of the observation period (31 December 1977), $12843(80 \cdot 7 \%)$ cohort members were identified as living. The cohort was relatively young, and only $499(3 \cdot 1 \%)$ were identified as deceased. Death certificates were obtained for $452(90.6 \%)$ of them. For the remaining 47 deaths, the date but not the cause of death was available. These 47 deaths were included in the overall SMR calculation, but not in any cause specific SMR analysis. At the close of the study period, the vital state of $2567(16 \cdot 1 \%)$ workers remained unknown. In the subsequent statistical analysis, person-years for these 2567 subjects lost to follow up were counted up to the date of last contact (for example, date of termination).

The per cent of cohort members with unknown vital state was relatively high. An examination of this percentage by plant did not show any concentration at any particular plant. Further investigation showed that per cent was higher in the women $(24 \cdot 1 \%)$ than in the men $(13.6 \%)$.

\section{TOTAL COHORT}

The total number of deaths, 499 , was nearly identical to the expected number of $498 \cdot 82$. The overall SMR for the entire cohort was $100 \cdot 0$. For either the entire cohort or each sex, no significant mortality from any specific cause was seen (table 1 ).

Mortality from cancer of all sites for the entire cohort was slightly less than the expected (88 observed $v 99.87$ expected deaths). A non-significant mortality deficit was found from cancer of the 
Table 1 Observed (Obs) deaths by cause and SMRs for workers in reinforced plastics industry

\begin{tabular}{|c|c|c|c|c|c|c|}
\hline \multirow[b]{2}{*}{ Cause of death (7th ICD) } & \multicolumn{2}{|c|}{ Total cohort } & \multicolumn{2}{|c|}{ Men workers } & \multicolumn{2}{|c|}{ Women workers } \\
\hline & Obs & $S M R$ & Obs & $S M R$ & Obs & $S M R$ \\
\hline All causes & 499 & $100 \cdot 0$ & 424 & $98 \cdot 1$ & 75 & $112 \cdot 7$ \\
\hline Infective \& parastic diseases $(000-138)$ & 5 & $109 \cdot 4$ & 4 & $106 \cdot 2$ & 1 & $124 \cdot 6$ \\
\hline All cancers $(140-205)$ & 88 & $88 \cdot 1$ & 68 & $87 \cdot 6$ & 20 & $90 \cdot 0$ \\
\hline Cancer of buccal cavity and pharynx (140-148) & 1 & $35 \cdot 1$ & 1 & $39 \cdot 2$ & 0 & - \\
\hline Cancer of digestive system $(150-159)$ & 20 & $89 \cdot 0$ & 14 & $75 \cdot 4$ & 6 & $153 \cdot 8$ \\
\hline Cancer of stomach (151) & 3 & $81 \cdot 6$ & 2 & $63 \cdot 3$ & 1 & 193.4 \\
\hline Cancer of large intestine (153) & 8 & $102 \cdot 5$ & 7 & 115.6 & 1 & $57 \cdot 2$ \\
\hline Cancer of rectum (154) & 2 & $82 \cdot 0$ & 2 & $98 \cdot 5$ & 0 & - \\
\hline Cancer of liver $(155-156)$ & 2 & $136 \cdot 0$ & 0 & - & 2 & $650 \cdot 1$ \\
\hline Cancer of pancreas (157) & 3 & $65 \cdot 4$ & 1 & $25 \cdot 5$ & 2 & 301.9 \\
\hline Cancer of respiratory system $(160-164)$ & 34 & $116 \cdot 1$ & 29 & $108 \cdot 5$ & 5 & 195.4 \\
\hline Cancer of larynx (161) & 4 & $341 \cdot 1$ & 4 & $360 \cdot 2$ & 0 & - \\
\hline Cancer of lung (162-163) & 30 & $108 \cdot 1$ & 25 & $98 \cdot 8$ & 5 & $204 \cdot 0$ \\
\hline Cancer of prostate (177) & 2 & $81 \cdot 9$ & 2 & $81 \cdot 9$ & 0 & - \\
\hline Cancer of breast (170) & 2 & $33 \cdot 1$ & 0 & - & 2 & $33 \cdot 1$ \\
\hline Cancer of all uterus (171) & 2 & $95 \cdot 4$ & 0 & - & 2 & $95 \cdot 4$ \\
\hline Cancer of kidney (180) & 2 & $86 \cdot 3$ & 2 & $98 \cdot 6$ & 0 & - \\
\hline Cancer of bladder (181) & 3 & $176 \cdot 7$ & $\overline{3}$ & $191 \cdot 6$ & 0 & - \\
\hline Cancer of skin $(190)$ & 3 & 113.7 & 3 & $138 \cdot 8$ & 0 & - \\
\hline Lymphatic and haematopoietic cancer (200-205) & 9 & $73 \cdot 3$ & 8 & $78 \cdot 7$ & 1 & $47 \cdot 4$ \\
\hline Lymphosarcoma and reticulosarcoma (200) & 0 & - & 0 & - & 0 & - \\
\hline Hodgkin's disease (201) & 3 & $124 \cdot 5$ & 3 & $147 \cdot 2$ & 0 & - \\
\hline Leukaemia \& aleukaemia (204) & 5 & $105 \cdot 1$ & 4 & $102 \cdot 2$ & 1 & $118 \cdot 5$ \\
\hline Diabetes mellitus (260) & 4 & $57 \cdot 6$ & 2 & 35.9 & 2 & $145 \cdot 4$ \\
\hline Diseases of blood and blood forming organs (290-299) & 1 & $85 \cdot 8$ & 1 & $111 \cdot 5$ & 0 & - \\
\hline Diseases of nervous system and sense organs $(330-398)$ & 30 & $106 \cdot 9$ & 25 & $110 \cdot 1$ & 5 & $93 \cdot 1$ \\
\hline Diseases of circulatory system $(400-468)$ & 154 & $92 \cdot 7$ & 137 & $90 \cdot 3$ & 17 & $117 \cdot 3$ \\
\hline Chronic rheumatic heart disease $(410-416)$ & 1 & $17 \cdot 6^{\star}$ & 0 & - & 1 & $70 \cdot 7$ \\
\hline Arteriosclerotic heart disease (inc CHD) (420) & 118 & 86.9 & 107 & $84 \cdot 7$ & 11 & $116 \cdot 0$ \\
\hline Non-malignant respiratory disease $(470-527)$ & 11 & $51 \cdot 8^{\star}$ & 11 & $59 \cdot 0$ & 0 & - \\
\hline Pneumonia $(490-493)$ & 2 & $23 \cdot 8^{\star}$ & 2 & $28 \cdot 0$ & 0 & - \\
\hline Emphysema (527) & 6 & $117 \cdot 7$ & 6 & $126 \cdot 6$ & 0 & - \\
\hline Diseases of digestive system $(530-587)$ & 21 & $75 \cdot 5$ & 17 & $72 \cdot 1$ & 4 & $94 \cdot 3$ \\
\hline Cirrhosis of liver (581) & 9 & $52 \cdot 5^{\star}$ & 7 & $48 \cdot 2^{\star}$ & 2 & 76.6 \\
\hline Diseases of genitourinary system $(590-639)$ & 7 & $129 \cdot 6$ & 5 & $116 \cdot 1$ & 2 & $182 \cdot 8$ \\
\hline Symptoms, senility and ill defined conditions $(780-795)$ & 3 & $39 \cdot 3$ & 2 & $30 \cdot 3$ & 1 & 95.9 \\
\hline Accidents, poisonings, and violence (E800-E999) & 121 & $103 \cdot 5$ & $10 \overline{8}$ & $101 \cdot 1$ & 13 & 129.9 \\
\hline Accidents (800-962) & 84 & $107 \cdot 3$ & 76 & 104.9 & 8 & $138 \cdot 2$ \\
\hline Motor vehicle accidents $(810-835)$ & 57 & $127 \cdot 3$ & 52 & $126 \cdot 0$ & 5 & $143 \cdot 1$ \\
\hline Suicide $(963,960-979)$ & 21 & $85 \cdot 9$ & 19 & $88 \cdot 4$ & 2 & $67 \cdot 6$ \\
\hline
\end{tabular}

${ }^{\star} \mathrm{p}<0.05$.

digestive system $($ SMR $=89.09)$. There was a slight non-significant mortality excess from cancer of the respiratory system (34 observed $v 29.28$ expected deaths). The SMR for respiratory cancer was $116 \cdot 1$ for the entire cohort, 108.5 for the men and 195.4 for the women (non-significant). Four deaths were due to cancer of the larynx among the men, giving an SMR of 360.2 , with a $p$ value close to 0.05 . The remaining 30 deaths were from lung cancer, which resulted in an SMR of 108.1 for the total cohort.

Although 12.28 deaths were expected from lymphatic and haematopoietic cancer, only nine deaths were seen. The corresponding SMR was $73 \cdot 3$, but the deficit was not statistically significant. The deficit came primarily from lymphosarcoma and reticulosarcoma, for which no death was seen but 2.63 were expected. Mortality from leukaemia was as expected (five expected $v 4.76$ deaths).

Mortality from diseases of the circulatory system was slightly less than expected $(S M R=92 \cdot 7)$. On the other hand, the deficit in non-malignant respiratory disease was statistically significant $(S M R=$
51.8). The deficit appeared to come from pneumonia $(S M R=23.8, p<0.05)$. The deficit for cirrhosis of the liver was also statistically significant (SMR = $52.5, \mathrm{p}<0.05)$.

\section{ANALYSIS OF DURATION OF EMPLOYMENT}

Table 2 shows the observed deaths and SMRs by cause and duration of employment for the entire cohort. For total mortality, the SMR decreased with increased duration of employment. For those who worked between six months and a year, the total SMR was $128.6(p<0.05)$ and for those with five or more years of employment, the overall SMR was 74.9 $(\mathrm{p}<0.05)$.

For respiratory cancer, the less than one year group showed the highest SMR (189.7). None of the respiratory cancer SMRs by duration of employment was significant, however. Among those who worked between six months and a year, three deaths from cancer of the larynx occurred, giving an SMR of $1612.1(p<0.01)$. All three deaths were among the male cohort members. 
Table 2 Observed (Obs) deaths and SMRs by cause and duration of employment for the entire cohort

\begin{tabular}{|c|c|c|c|c|c|c|c|c|}
\hline \multirow[b]{3}{*}{ Cause of death (7th ICD) } & \multicolumn{8}{|c|}{ Duration of employment (y) } \\
\hline & \multicolumn{2}{|l|}{$<1$} & \multicolumn{2}{|l|}{$1-2$} & \multicolumn{2}{|l|}{$2-5$} & \multicolumn{2}{|l|}{$>5$} \\
\hline & Obs & $S M R$ & Obs & $S M R$ & Obs & $S M R$ & Obs & $S M R$ \\
\hline All causes & 127 & $128 \cdot 6$ & 109 & $117 \cdot 1$ & 127 & $101 \cdot 2$ & 136 & $74 \cdot 9 \star \star$ \\
\hline All cancers $(140-205)$ & 22 & $124 \cdot 7$ & 19 & 111.9 & 24 & $97 \cdot 4$ & 23 & $56 \cdot 6^{\star \star}$ \\
\hline Cancer of digestive system (150-159) & 4 & $107 \cdot 4$ & 5 & $136 \cdot 1$ & 5 & $91 \cdot 1$ & 6 & $62 \cdot 6$ \\
\hline Cancer of stomach (151) & 1 & $164 \cdot 1$ & 1 & $162 \cdot 8$ & 0 & - & 1 & $64 \cdot 8$ \\
\hline Cancer of large intestine (153) & 1 & $76 \cdot 7$ & 2 & $158 \cdot 4$ & 2 & $104 \cdot 2$ & 3 & $90 \cdot 4$ \\
\hline Cancer of respiratory system $(160-164)$ & 9 & $189 \cdot 7$ & 4 & $83 \cdot 1$ & 11 & $161 \cdot 7$ & 10 & $77 \cdot 4$ \\
\hline Cancer of larynx (161) & 3 & $1612 \cdot 1 \star \star$ & 1 & $521 \cdot 2$ & 0 & - & 0 & - \\
\hline Cancer of lung (162-163) & 6 & 133.6 & 3 & 65.9 & 11 & $170 \cdot 7$ & 10 & $81 \cdot 5$ \\
\hline Lymphatic and haematopoietic cancer $(200-205)$ & 1 & $38 \cdot 7$ & 3 & $126 \cdot 0$ & 4 & $127 \cdot 4$ & 1 & $24 \cdot 0$ \\
\hline Hodgkin's disease (201) & 1 & $168 \cdot 5$ & 1 & $188 \cdot 3$ & 1 & $153 \cdot 0$ & 0 & - \\
\hline Leukaemia and aleukaemia (204) & 0 & - & 2 & $213 \cdot 3$ & 2 & 163.4 & 1 & 63.7 \\
\hline Diseases of nervous system and sense organs $(330-398)$ & 7 & $138 \cdot 7$ & 6 & $124 \cdot 1$ & 6 & $83 \cdot 7$ & 11 & $99 \cdot 8$ \\
\hline Diseases of circulatory system $(400-468)$ & 31 & $112 \cdot 8$ & 27 & 97.5 & 47 & $116 \cdot 8$ & 49 & $69 \cdot 2^{\star \star}$ \\
\hline Arteriosclerotic heart disease (inc CHD) (420) & 27 & $122 \cdot 4$ & 17 & 75.9 & 37 & $113 \cdot 7$ & 37 & $62 \cdot 9 \star \star$ \\
\hline Non-malignant respiratory disease $(470-527)$ & 3 & $80 \cdot 6$ & 4 & $110 \cdot 2$ & 2 & $38 \cdot 5$ & 2 & $23 \cdot 0^{\star}$ \\
\hline Pneumonia (490-493) & 1 & $62 \cdot 6$ & 1 & $65 \cdot 7$ & 0 & - & 0 & - \\
\hline Emphysema (527) & 1 & $128 \cdot 4$ & 3 & 374.9 & 1 & $83 \cdot 1$ & 1 & $43 \cdot 2$ \\
\hline Diseases of digestive system $(530-587)$ & 6 & $117 \cdot 5$ & 4 & $80 \cdot 3$ & 3 & 43.4 & 8 & $74 \cdot 0$ \\
\hline Accidents, poisonings, and violence (E800-E999) & 31 & $97 \cdot 9$ & 36 & $131 \cdot 0$ & 28 & 89.5 & 26 & $98 \cdot 4$ \\
\hline Accidents (800-962) & 22 & $100 \cdot 8$ & 24 & $128 \cdot 1$ & 21 & $100 \cdot 3$ & 17 & $101 \cdot 5$ \\
\hline Motor vehicle accidents $(810-835)$ & 15 & 113.4 & 16 & $143 \cdot 7$ & 13 & $107 \cdot 9$ & 13 & $155 \cdot 5$ \\
\hline
\end{tabular}

No trend, either upward or downward, was seen for lymphatic and haematopoietic cancer, or for leukaemia. None of the SMRs by any duration of employment was significant for these two categories of diseases for the entire cohort.

\section{ANALYSIS BY LATENCY}

Table 3 represents the observed deaths and SMRs by cause for the entire cohort by latency since hire. An upward trend was detected for cancer of the lung, ranging from an SMR of 74.0 for a latency of less than 10 years, through 123.3 for $10-19$ years, to 209.5 for 20-29 years; although none of the SMRs was statistically sigificant. To further examine the pattern of mortality from lung cancer, analysis by sex and duration of employment among cohort members with at least 20 years of latency was performed (table 4). Statistically significant lung cancer SMRs were found for men with two to five years of employment and at least 20 years of latency $(S M R=716.5, p<$ 0.05 ), and for women with a latency of at least 20 years $(S M R=1382 \cdot 8, p<0.01)$.

The other upward trend shown in table 3 was that for non-malignant respiratory disease. Although there was an upward trend, none of the three SMRs was more than the expected. In fact, for the group with less than 10 years of latency, the SMR was 35.9 $(\mathrm{p}<0.05)$.

\section{ANALYSIS BY DEPARTMENT EXPOSURE}

The following were considered departments with high exposure potential; mixing; SMC manufacturing, injection moulding, gel coating, spray up and lay up, winding, casting, centrifugal casting, and pul- trusion. The departments with low exposure potential included general non-production, cut, weight, and press, finishing, store and ship, string and fit, foaming, mould preparation, field service, and preform production. According to this classification, 4754 cohort members were employed in high exposure departments and 9049 were employed in low exposure departments. It was impossible to classify 2105 workers by this scheme, because the magnitude of their departmental exposure was unknown.

Table 5 shows the observed deaths and SMRs by cause for departments with high or low exposure. A considerable difference in SMR for lung cancer was seen between the groups. The high exposure group experienced a lung cancer SMR of $69 \cdot 4$ (three observed deaths; non-significant, compared with an SMR of $128 \cdot 2$ (23 observed deaths; non-significant) for the low exposure groups. For leukaemia, the SMR in the high exposure group was 199.3 (two observed deaths; non-significant) and that in the low exposure group was $99 \cdot 3$ (three observed deaths; non-significant), indicating a $2-14$ fold difference between the two groups. This observation was based on small numbers of observed deaths, however, and the difference was not statistically significant. No death due to Hodgkin's disease was found in the high exposure group, but the SMR for the low exposure group was 197.9 (three observed deaths; nonsignificant).

\section{ANALYSIS BY TWA}

Cohort members were classified according to the maximum (highest) TWA they were ever exposed to throughout their work histories. An arbitrary div- 
Table 3 Observed (Obs) deaths and SMRs by cause and latency for the entire cohort

\begin{tabular}{|c|c|c|c|c|c|c|}
\hline \multirow[b]{3}{*}{ Cause of death (7th ICDA) } & \multicolumn{6}{|c|}{ Latency $(y)$} \\
\hline & \multicolumn{2}{|c|}{$<10$} & \multicolumn{2}{|c|}{$10-19$} & \multicolumn{2}{|c|}{$20 \cdot 29$} \\
\hline & Obs & $S M R$ & Obs & $S M R$ & Obs & $S M R$ \\
\hline All causes & 303 & $103 \cdot 7$ & 156 & 96.9 & 40 & $95 \cdot 9$ \\
\hline All cancers $(140-205)$ & 48 & $90 \cdot 2$ & 29 & $81 \cdot 5$ & 11 & $108 \cdot 7$ \\
\hline Cancer of digestive system $(150-159)$ & 12 & $104 \cdot 8$ & 5 & $60 \cdot 0$ & 3 & $122 \cdot 5$ \\
\hline Cancer of stomach (151) & 2 & $103 \cdot 4$ & 0 & - & 1 & $267 \cdot 1$ \\
\hline Cancer of large intestine (153) & 4 & $101 \cdot 8$ & 3 & $102 \cdot 6$ & 1 & $114 \cdot 3$ \\
\hline Cancer of respiratory system $(160-164)$ & 12 & 83.9 & 14 & $126 \cdot 2$ & 8 & $228 \cdot 4$ \\
\hline Cancer of larynx (161) & 2 & $344 \cdot 6$ & 1 & $227 \cdot 4$ & 1 & $732 \cdot 9$ \\
\hline Cancer of lung (162-163) & 10 & $74 \cdot 0$ & 13 & $123 \cdot 3$ & 7 & $209 \cdot 5$ \\
\hline Lymphatic and haematopoietic cancer (200-205) & 7 & $92 \cdot 5$ & 2 & $53 \cdot 6$ & 0 & - \\
\hline Hodgkin's disease (201) & 3 & $172 \cdot 0$ & 0 & - & 0 & - \\
\hline Leukaemia and aleukaemia (204) & 4 & 133.9 & 1 & $71 \cdot 1$ & 0 & - \\
\hline Diseases of nervous system and sense organs $(330-398)$ & 17 & $111 \cdot 7$ & 10 & $101 \cdot 4$ & 3 & $109 \cdot 1$ \\
\hline Diseases of circulatory system $(400-468)$ & 88 & 103.7 & 52 & $84 \cdot 4$ & 14 & $78 \cdot 4$ \\
\hline Arteriosclerotic heart disease (inc CHD) (420) & 66 & $97 \cdot 1$ & 42 & $82 \cdot 1$ & 10 & $66 \cdot 2$ \\
\hline Non-malignant respiratory disease $(470-527)$ & 4 & $35 \cdot 9 \star$ & 5 & 65.9 & 2 & $87 \cdot 9$ \\
\hline Pneumonia $(490-493)$ & $i$ & $21 \cdot 0$ & 1 & $35 \cdot 6$ & 0 & - \\
\hline Emphysema (527) & 2 & $82 \cdot 1$ & 3 & $151 \cdot 4$ & 1 & $164 \cdot 8$ \\
\hline Diseases of digestive system $(530-587)$ & 13 & $84 \cdot 3$ & 6 & $61 \cdot 3$ & 2 & 83.4 \\
\hline Accidents, poisonings, and violence (E800-E999) & 92 & $104 \cdot 1$ & 27 & $109 \cdot 5$ & 2 & $56 \cdot 1$ \\
\hline Accidents (800-962) & 64 & $105 \cdot 5$ & 19 & $124 \cdot 2$ & 1 & $46 \cdot 6$ \\
\hline Motor vehicle accidents $(810-835)$ & 44 & $121 \cdot 1$ & 12 & $160 \cdot 1$ & 1 & $111 \cdot 6$ \\
\hline
\end{tabular}

${ }^{\star} \mathrm{p}<0 \cdot 05$.

ision of less than $20 \mathrm{ppm}$ (lower) and greater than 20 ppm (higher) was used in the classification, dividing the cohort into two roughly equal groups; 7373 in the lower maximum and 7866 in the higher maximum TWA group (the maximum TWA of 669 workers could not be determined).

Table 6 shows the cause specific mortality experience of the cohort by maximum TWA. The SMR in the higher maximum TWA group (SMR = 84.5) was lower than that in the lower maximum TWA group $(S M R=141 \cdot 5)$. The difference was even larger when only lung cancer was considered (59.4 $v$ 143.5). In the higher maximum TWA group, three deaths were due to cancer of the larynx when only 0.41 were expected. The corresponding SMR of 730.5 was statistically significant.

A considerable difference in mortality from leuk- aemia existed between the two groups. The SMR for leukaemia in the lower maximum TWA group was 39.9 (one observed death) and that in the higher maximum TWA group was $200 \cdot 4$ (four observed deaths), a fivefold difference between the two groups; but the numbers of deaths were few, and the difference was not statistically significant. For all lymphopoietic cancer, the difference between the two groups was much smaller (SMR $=61.3$ in the lower group $v 98 \cdot 1$ in the higher group).

Workers were also classified according to the average TWA (weighted by duration) throughout their work histories. A total of 6545 workers were classified in the higher average TWA $(>12 \mathrm{ppm})$ and 8694 in the lower average TWA $(<12 \mathrm{ppm})$. The 669 workers with ill defined exposure levels were not included in this analysis.

Table 4 Observed and expected deaths, SMRs, and 95\% CI for lung cancer among cohort members with at least 20 years latency by sex and duration of employment

\begin{tabular}{|c|c|c|c|c|c|}
\hline \multirow[b]{2}{*}{ Variable } & \multicolumn{5}{|c|}{ Duration of employment (y) } \\
\hline & $<1$ & $1-2$ & $2-5$ & $>5$ & Total \\
\hline \multicolumn{6}{|c|}{ Men } \\
\hline Observed deaths & 0 & 0 & 3 & 0 & \\
\hline Expected deaths & $0 \cdot 28$ & $0 \cdot 34$ & 0.42 & $2 \cdot 01$ & $\begin{array}{r}3.05 \\
08.3\end{array}$ \\
\hline $\begin{array}{l}\text { SMR } \\
95 \% \mathrm{CI}\end{array}$ & $\overline{-}$ & 二 & $\begin{array}{l}716 \cdot 5^{\star} \\
147 \cdot 7-2095 \cdot 0\end{array}$ & 二 & $\begin{array}{l}98 \cdot 3 \\
20 \cdot 3-287 \cdot 4\end{array}$ \\
\hline \multicolumn{6}{|c|}{ Women } \\
\hline Observed deaths & 2 & 0 & 1 & 1 & 4 \\
\hline Expected deaths & & 0.03 & 0.06 & $0 \cdot 15$ & 0.29 \\
\hline SMR & $4192 \cdot 7^{\star}$ & - & 1693.6 & $655 \cdot 2$ & $1382 \cdot 8^{\star \star}$ \\
\hline $95 \% \mathrm{CI}$ & $507 \cdot 6-15136 \cdot 0$ & - & $42 \cdot 8-9408 \cdot 9$ & $16 \cdot 6-3640 \cdot 2$ & $376.8-3536.6$ \\
\hline
\end{tabular}

${ }^{\star} \mathrm{p}<0.05 ;{ }^{\star \star} \mathrm{p}<0.01$. 
Table 5 Observed (Obs) deaths and SMRs for the cohort by cause and departmental exposure

\begin{tabular}{|c|c|c|c|c|}
\hline \multirow[b]{2}{*}{ Cause of death (7th ICD) } & \multicolumn{2}{|c|}{ Low exposure potential } & \multicolumn{2}{|c|}{ High exposure potential } \\
\hline & Obs & $S M R$ & Obs & $S M R$ \\
\hline $\begin{array}{l}\text { All causes } \\
\text { All cancers (140-205) } \\
\text { Cancer of digestive system (150-159) } \\
\text { Cancer of stomach (151) } \\
\text { Cancer of large intestine (153) } \\
\text { Cancer of respiratory system (160-164) } \\
\text { Cancer of larynx (161) } \\
\text { Cancer of lung (162-163) } \\
\text { Lymphatic and haematopoietic cancer (200-205) } \\
\text { Hodgkin's Disease (201) } \\
\text { Leukaemia and aleukaemia (204) } \\
\text { Diseases of nervous system (330-398) } \\
\text { Diseases of circulatory system (400-468) } \\
\text { Arteriosclerotic heart disease (420) } \\
\text { Non-malignant respiratory disease (470-529) } \\
\text { Pneumonia (490-493) } \\
\text { Emphysema (527) } \\
\text { Diseases of digestive system (530-587) } \\
\text { Accidents, poisonings, and violence (E800-E999) } \\
\text { Accidents (800-962) } \\
\text { Motor vehicle accidents (810-835) }\end{array}$ & $\begin{array}{r}335 \\
63 \\
17 \\
2 \\
7 \\
26 \\
3 \\
23 \\
7 \\
3 \\
3 \\
23 \\
100 \\
82 \\
6 \\
1 \\
4 \\
8 \\
82 \\
52 \\
34\end{array}$ & $\begin{array}{c}106 \cdot 4 \\
97 \cdot 4 \\
117 \cdot 1 \\
84 \cdot 3 \\
138 \cdot 8 \\
137 \cdot 4 \\
396 \cdot 0 \\
128 \cdot 2 \\
89.7 \\
197 \cdot 9 \\
99.9 \\
129.5 \\
93.8 \\
94 \cdot 1 \\
44.3 \star \\
18.8 \\
122.3 \\
44.5 \star \\
117.6 \\
111.6 \\
128.8\end{array}$ & $\begin{array}{r}85 \\
13 \\
2 \\
1 \\
0 \\
4 \\
1 \\
3 \\
2 \\
0 \\
2 \\
2 \\
24 \\
16 \\
2 \\
1 \\
1 \\
8 \\
25 \\
19 \\
13\end{array}$ & $\begin{array}{r}88 \cdot 3 \\
73 \cdot 3 \\
55 \cdot 7 \\
175 \cdot 9 \\
\\
87 \cdot 8 \\
589 \cdot 5 \\
69 \cdot 4 \\
79 \cdot 0 \\
199 \cdot 3 \\
41 \cdot 2 \\
94 \cdot 7 \\
79 \cdot 0 \\
57 \cdot 7 \\
65 \cdot 6 \\
149 \cdot 7 \\
155 \cdot 0 \\
78 \cdot 6 \\
88 \cdot 4 \\
101 \cdot 2\end{array}$ \\
\hline
\end{tabular}

${ }^{\star} \mathrm{p}<0.05$.

No of persons $=13803$.

As indicated in table 6, whereas the overall SMR for the higher average TWA group (90.2) was lower than that for the lower average TWA group (100.8), the reverse was true for cancer of all sites $(97.9 v 85.4$ deaths), and for digestive cancer (126.2 $v 81.9$ deaths).

Three deaths in the higher average TWA group were due to cancer of the larynx, giving a statistically significant SMR of 941.1 ( $<<0.01)$, whereas only one death in the lower average TWA group was ascribed to cancer of the larynx, with a corresponding
SMR of 127.9 (non-significant). For lung cancer, a non-significant deficit was seen in the higher group (SMR $=64 \cdot 0$, five observed deaths), but the SMR in the lower group was increased $(\mathrm{SMR}=131 \cdot 1,24$ observed deaths).

A difference in mortality from leukaemia was detected between the two groups. In the lower average TWA group, the leukaemia SMR was 33.8 (one observed death) and that in the higher group was 259.6 (four observed deaths), a ratio of more than sevenfold. Both SMRs, however, were based on a

Table 6 Observed (Obs) deaths and SMRs for the cohort by cause and maximum TWA or average TWA

\begin{tabular}{|c|c|c|c|c|c|c|c|c|}
\hline \multirow[b]{3}{*}{ Cause of death (7th ICD) } & \multicolumn{4}{|c|}{ Maximum $T W A$} & \multicolumn{4}{|c|}{ Average $T W A$} \\
\hline & \multicolumn{2}{|c|}{ Lower max $T W A$} & \multicolumn{2}{|c|}{ Higher max $T W A$} & \multicolumn{2}{|c|}{ Lower avg $T W A$} & \multicolumn{2}{|c|}{ Higher avg $T W A$} \\
\hline & Obs & $S M R$ & Obs & $S M R$ & Obs & $S M R$ & Obs & $S M R$ \\
\hline $\begin{array}{l}\text { All causes } \\
\text { All cancers (140-205) } \\
\text { Cancer of digestive system (150-159) } \\
\text { Cancer of stomach (151) } \\
\text { Cancer of large intestine (153) } \\
\text { Cancer of respiratory system (160-164) } \\
\text { Cancer of larynx (161) } \\
\text { Cancer of lung (162-163) } \\
\text { Lymphatic and haematopoietic cancer (200-205) } \\
\text { Hodgkin's disease (201) } \\
\text { Leukaemia and aleukaemia (204) } \\
\text { Diseases of nervous system (330-398) } \\
\text { Diseases of circulatory system (400-468) } \\
\text { Arteriosclerotic heart disease (420) } \\
\text { Non-malignant respiratory disease (470-529) } \\
\text { Pneumonia (490-493) } \\
\text { Emphysema (527) } \\
\text { Diseases of digestive system (530-587) } \\
\text { Accidents, poisonings, and violence (E800-E999) } \\
\text { Accidents ( } 800-962) \\
\text { Motor vehicle accidents ( } 810-835)\end{array}$ & $\begin{array}{r}277 \\
49 \\
10 \\
1 \\
5 \\
24 \\
1 \\
23 \\
4 \\
3 \\
1 \\
17 \\
94 \\
72 \\
5 \\
0 \\
5 \\
9 \\
63 \\
39 \\
23\end{array}$ & $\begin{array}{r}102 \cdot 3 \\
89 \cdot 3 \\
79 \cdot 0 \\
47 \cdot 9 \\
115 \cdot 7 \\
141 \cdot 9 \\
144 \cdot 9 \\
143 \cdot 5 \\
61 \cdot 3 \\
244 \cdot 3 \\
39 \cdot 9 \\
111 \cdot 0 \\
98 \cdot 6 \\
91 \cdot 7 \\
41 \cdot 8 \star \\
166 \cdot 3 \\
58 \cdot 9 \\
109 \cdot 5 \\
101 \cdot 4 \\
106.5\end{array}$ & $\begin{array}{r}180 \\
35 \\
10 \\
2 \\
3 \\
9 \\
3 \\
6 \\
5 \\
0 \\
4 \\
9 \\
42 \\
34 \\
4 \\
2 \\
1 \\
10 \\
52 \\
39 \\
28\end{array}$ & $\begin{array}{c}90.5 \\
89.4 \\
119.9 \\
149.9 \\
100 \cdot 8 \\
84.5 \\
730.5^{\star} \\
59 \cdot 4 \\
98 \cdot 1 \\
200 \cdot 4 \\
83.6 \\
70.5 \star \\
70.6^{\star} \\
50.4 \\
61.0 \\
57 \cdot 3 \\
91.3 \\
95.5 \\
106.7 \\
130.7\end{array}$ & $\begin{array}{r}318 \\
55 \\
12 \\
2 \\
5 \\
5 \\
25 \\
1 \\
24 \\
5 \\
3 \\
1 \\
20 \\
107 \\
84 \\
5 \\
0 \\
5 \\
11 \\
73 \\
45 \\
29\end{array}$ & 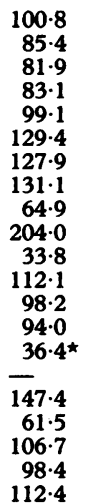 & $\begin{array}{r}139 \\
29 \\
8 \\
1 \\
3 \\
8 \\
3 \\
5 \\
4 \\
0 \\
4 \\
6 \\
29 \\
22 \\
4 \\
2 \\
1 \\
8 \\
42 \\
33 \\
22\end{array}$ & $\begin{array}{c}90 \cdot 2 \\
97.9 \\
126 \cdot 2 \\
98 \cdot 5 \\
133.4 \\
97 \cdot 1 \\
941 \cdot 1 \star \star \\
64 \cdot 0 \\
102 \cdot 0 \\
259.6 \\
72 \cdot 8 \\
63 \cdot 1 \star \star \\
59.0 \star \star \\
65 \cdot 1 \\
79 \cdot 1 \\
73.6 \\
95.9 \\
96.4 \\
112.8 \\
127.8\end{array}$ \\
\hline
\end{tabular}

${ }^{\star} p<0.05 ;{ }^{\star \star} p<0.01$ 
Table 7 Observed (Obs) deaths and SMRs for the cohort by hot and cold process

\begin{tabular}{|c|c|c|c|c|}
\hline & \multicolumn{2}{|l|}{ Cold } & \multicolumn{2}{|l|}{ Hot } \\
\hline & Obs & $S M R$ & Obs & $S M R$ \\
\hline $\begin{array}{l}\text { All causes } \\
\text { All cancers (140-205) } \\
\text { Cancer of digestive system (150-159) } \\
\text { Cancer of stomach }(151) \\
\text { Cancer of large intestine (153) } \\
\text { Cancer of respiratory system (160-164) } \\
\text { Cancer of larynx (161) } \\
\text { Cancer of lung (162-163) } \\
\text { Lymphatic and haematopoietic cancer (200-205) } \\
\text { Hodgkin's disease (201) } \\
\text { Leukaemia and aleukaemia (204) } \\
\text { Diseases of nervous system (330-398) } \\
\text { Diseases of circulatory system (400-468) } \\
\text { Arteriosclerotic heart disease (420) } \\
\text { Non-malignant respiratory disease (470-529) } \\
\text { Pneumonia (490-493) } \\
\text { Emphysema (527) } \\
\text { Diseases of digestive system (530-587) } \\
\text { Accidents, poisonings, and violence (E800-E999) } \\
\text { Accidents (800-962) } \\
\text { Motor vehicle accidents (810-835) }\end{array}$ & $\begin{array}{r}162 \\
32 \\
9 \\
1 \\
4 \\
9 \\
2 \\
7 \\
3 \\
1 \\
2 \\
10 \\
47 \\
36 \\
6 \\
2 \\
3 \\
10 \\
35 \\
27 \\
17\end{array}$ & $\begin{array}{r}89 \cdot 9 \\
93 \cdot 1 \\
111 \cdot 7 \\
75 \cdot 4 \\
147 \cdot 8 \\
78 \cdot 3 \\
423 \cdot 1 \\
64 \cdot 2 \\
71 \cdot 5 \\
129 \cdot 1 \\
122 \cdot 8 \\
101 \cdot 9 \\
74 \cdot 3 \star \\
68 \cdot 3 \star \\
74 \cdot 9 \\
66 \cdot 8 \\
145 \cdot 0 \\
103 \cdot 7 \\
83 \cdot 1 \\
95 \cdot 9 \\
105 \cdot 7\end{array}$ & $\begin{array}{r}260 \\
49 \\
8 \\
2 \\
3 \\
24 \\
2 \\
22 \\
5 \\
1 \\
3 \\
16 \\
78 \\
59 \\
3 \\
0 \\
1 \\
10 \\
67 \\
43 \\
27\end{array}$ & $\begin{array}{c}106 \cdot 0 \\
97 \cdot 0 \\
73 \cdot 2 \\
111 \cdot 8 \\
77 \cdot 6 \\
177 \cdot 9 \star \\
378 \cdot 8 \\
172 \cdot 1 \\
79 \cdot 2 \\
76 \cdot 6 \\
122 \cdot 7 \\
116 \cdot 0 \\
100 \cdot 5 \\
94 \cdot 5 \\
30 \cdot 1 \\
- \\
45 \cdot 3 \\
70 \cdot 2 \\
113 \cdot 7 \\
109 \cdot 0 \\
119 \cdot 6\end{array}$ \\
\hline
\end{tabular}

${ }^{\star} \mathrm{p}<0.05$.

No of persons $=13923$.

small number of observed deaths. On the other hand, mortality from Hodgkin's disease was raised in the lower group (SMR = 204.0, three observed deaths), whereas no death due to Hodgkin's disease occurred in the higher group.

\section{ANALYSIS BY HOT AND COLD PROCESS}

The reinforced plastics and composites processes were classified by the industrial hygienists in the industry into either "hot" (injection moulding, centrifugal compression moulding, continuous lamination, and pultrusion) or "cold" (resin mixing, lay up and spray up, bag moulding, and filament winding). In this analysis, each plant was classified by process, based on information from the plants; hot process only (seven plants), cold process only (19 plants), and both (four plants). Table 7 compares the cause specific mortality between the "hot only" and "cold only" process plants. A total of 6558 workers were exposed to the cold process only, and 7365 to the hot process only.

Overall mortality was lower for the cold process plants (SMR $=89.9)$ than for the hot process plants $(S M R=160 \cdot 0)$. For cancer of all sites, mortality was comparable between the two groups. Mortality from digestive cancer was slightly higher in the cold process group than in the hot process group (SMRs $=111.7$ and 73.2 ).

Mortality from lung cancer was less than expected in the cold process group (SMR $=64 \cdot 2$, seven observed deaths), whereas a significant excess of lung cancer was found for the hot process group (SMR = $172 \cdot 1,22$ observed deaths, $p<0.05$ ). The ratio between the two SMRs was more than $2 \cdot 5$. Mortality from cancer of the larynx was high in both groups (SMR $=423.1$ in the cold process group and 378.8 in the hot process group, neither SMR being significant).

Mortality from lymphopoietic cancer and leukaemia was comparable in both groups. On the other hand, mortality from diseases of the circulatory system was lower in the cold process group (SMR = $74.3, \mathrm{p}<0.05)$ than in the hot process group (SMR $=100 \cdot 5)$. Finally, mortality from non-malignant respiratory disease in the cold process group (SMR $=74.9$, six observed deaths) was higher than in the hot process group (SMR $=30 \cdot 1$, three observed deaths, $\mathrm{p}<0.05$ ).

\section{Case-control study of respiratory cancer}

In the cohort study, statistically significant SMRs for respiratory cancer were detected in several subgroups. For example, a twofold difference in SMR for respiratory cancer occurred between hot (SMR $=177, \mathrm{p}<0.05)$ and cold $(\mathrm{SMR}=78)$ process plants. This finding was not consistent with the concept that greater styrene exposure might cause a higher risk of respiratory cancer, as potential exposure to styrene from hot processes was less than that from cold processes. To investigate further the problem of respiratory cancer, a nested case-control study was conducted.

The cases were deaths from respiratory cancer. For each case, a maximum of three controls were selected from deceased members of the cohort, matched with respect to plant, age at death (within five years), year of death (within five years), sex, and race (from death certificates). The decision to use 
dead controls was based on a consideration of comparability of data to be collected for cases and controls.

The following information on the cases and controls was collected; any additional or more detailed work history; exposure on each job segment regarding hot or cold processes, resins, and other chemicals, exposures from employment outside of the plastics industry, and smoking history. Data sources included employment records, company medical records, health insurance records, and inquiries or interviews with persons who might be able to provide information on the study subjects such as fellow workers or next of kin.

Relative risks (approximated by odds ratios) were computed for each of the factors included for analysis. For dichotomous variables (for example, hot $v$ cold process), the Mantel-Haenszel $\chi^{2}$ procedure was used. ${ }^{12}$ For polychotomous variables (for example, years of exposure), the extension of the Mantel-Haenszel procedure was used. ${ }^{13}$ To examine the data for possible interaction among the variables, the data set was analysed by the multiple logistic regression technique. ${ }^{1415}$

Although 44 deaths (including those after the end of observation but known to us) in the cohort study were attributed to respiratory cancer, only 40 deaths from respiratory cancer were included in the casecontrol study analysis, because for four cases, no eligible controls could be found. These four cases were all from small plants, for which the number of deaths was small and the availability of potential controls was limited. Some of the 40 cases of respiratory cancer included in the analysis had only one or two, instead of three matched controls, because no more eligible controls could be found. A total of 40 cases and 102 matched controls were included in the analysis.

Although every cohort member in the study had to have had a minimum of six months of employment in an area or areas with potential exposure to styrene to be eligible for the study, not every cohort member actually worked in activities which entailed direct and significant exposure to styrene. Location desig- nations in the work history in employment records might not be specific enough and some sub areas within the production areas might not have any direct and significant exposure to styrene. In the casecontrol study, a detailed review (without knowing the case or control state) of work history regarding direct styrene exposure was done.

The Mantel-Haenszel relative risk between respiratory cancer and direct exposure to styrene was 0.63 , with $\chi^{2}$ of 1.11 (table 8). An analysis by duration of direct styrene exposure based on the MantelHaenszel extension $\chi^{2}$ procedure was also performed. The summary $\chi^{2}$ was 0.43 , indicating a lack of association between duration of styrene exposure and respiratory cancer mortality. Thus the analysis did not demonstrate any association between respiratory cancer and exposure to styrene.

Analysis from the cohort mortality study indicated that plants with hot process jobs experienced a higher rate of respiratory cancer than plants with cold process jobs. Table 8 shows that, adjusting for plant, there was no difference in risk for respiratory cancer between workers exposed to the hot processes and other workers. The type of process was, however, partly confounded by the variable "plant," which was in turn confounded with other concomitant exposures, availability of exposure histories, methods of exposure classification etc. Few plants had both hot and cold processes, and they did not contribute an adequate number of cases for a separate analysis.

A relative risk was also calculated by comparing those exposed to polyester resins with those unexposed (table 8). Although exposure of workers to styrene in the reinforced plastics industry was almost always through polyester resins, two workers directly exposed to styrene were not exposed to these resins. The relative risk for polyester resins was $0.55\left(\chi^{2}=\right.$ $1 \cdot 86, p=0 \cdot 17)$. Thus no association was found between exposure to polyester resins and respiratory cancer.

A similar analysis was done for exposure to acetone (table 8). The corresponding relative risk was $0.84\left(\chi^{2}\right.$ $=0 \cdot 18, p=0 \cdot 67)$. Again, no association was found

Table 8 Mantel-Haenszel relative risk and $\chi^{2}$ for respiratory cancer, various occupational exposures, and smoking

\begin{tabular}{|c|c|c|c|c|c|c|}
\hline & Occupational exposure & Cases & Controls & Relative risk & $\chi^{2}$ & $p$-Value \\
\hline Direct exposure to styrene & $\begin{array}{l}\text { Exposed } \\
\text { Not exposed }\end{array}$ & $\begin{array}{l}15 \\
25\end{array}$ & $\begin{array}{l}44 \\
58\end{array}$ & 0.63 & $1 \cdot 11$ & 0.29 \\
\hline Type of styrene process & $\begin{array}{l}\text { Hot only } \\
\text { Cold only or both }\end{array}$ & $\begin{array}{r}8 \\
32\end{array}$ & $\begin{array}{l}23 \\
79\end{array}$ & 0.69 & 0.04 & 0.52 \\
\hline Type of styrene process & $\begin{array}{l}\text { Hot only or both } \\
\text { Cold only }\end{array}$ & $\begin{array}{r}8 \\
32\end{array}$ & $\begin{array}{l}24 \\
78\end{array}$ & 0.65 & 0.57 & 0.46 \\
\hline Poly resins & $\begin{array}{l}\text { Exposed } \\
\text { Not exposed }\end{array}$ & $\begin{array}{l}14 \\
26\end{array}$ & $\begin{array}{l}45 \\
57\end{array}$ & 0.55 & 1.33 & $0 \cdot 25$ \\
\hline Acetone exposure & $\begin{array}{l}\text { Exposed } \\
\text { Not exposed }\end{array}$ & $\begin{array}{l}17 \\
23\end{array}$ & $\begin{array}{l}50 \\
52\end{array}$ & 0.84 & 0.03 & 0.87 \\
\hline Smoking & $\begin{array}{l}\text { Ever smoked } \\
\text { Never smoked }\end{array}$ & $\begin{array}{r}30 \\
1\end{array}$ & $\begin{array}{l}52 \\
11\end{array}$ & $7 \cdot 33$ & $4 \cdot 27$ & 0.04 \\
\hline
\end{tabular}


between exposure to acetone and respiratory cancer.

Smoking history was ascertained for $78.2 \%$ of the study subjects. A total of 31 matched sets had smoking information for both the case and the controls, and, therefore, could be included in the analysis. The relative risk of respiratory cancer for smokers (cigarettes, pipes, or cigars) was 7.33 when compared with non-smokers (table 8). The corresponding $\chi^{2}$ was $4 \cdot 27$, and the $p$ value was 0.04 . It is reassuring that the study, even with its relatively small sample size, did confirm the well established relation between smoking and respiratory cancer. Thus smoking was the only factor found to be associated with respiratory cancer in this study.

To determine if any interaction existed between the factors, they were examined simultaneously with a multiple logistic regression technique. Smoking, direct exposure to styrene, duration of exposure to styrene, and type of process were included in the multivariate model as main effects, and the effect due to the interaction terms was also examined. The results indicate that, among the factors included, only smoking showed a significant $\chi^{2}\left(\chi^{2}=4 \cdot 42, \mathrm{p}=\right.$ $0.04)$; and the corresponding goodness of fit $\chi^{2}$ was not statistically significant, meaning that the model fits the data reasonably well. Also, none of the interaction terms were significant. The results of this multiple logistic regression analysis were similar to those in table 8.

\section{Discussion and conclusion}

Although the observation period for the cohort study spanned a 31 year interval, the average duration of follow up for cohort members was relatively short (7.7 years). Also, the cohort was young compared with most other occupational studies. Half of the cohort entered the study before age 25 .

The vital state of cohort members was determined through the usual source, plant and company records, as well as the Social Security Administration (SSA). The vital state of a relatively large number of workers $(16 \cdot 1 \%)$ was undetermined. The reason for this high percentage lost to follow up was unclear. One explanation might be that the cohort included female employees, who might not be actively employed or might have married and changed their names by the end of the study. For these, the SSA follow up would not be productive. It was also noted that the cohort consisted of a high percentage of short term employees. These transient workers may also have contributed to the high percentage of lost to follow up.

The overall SMR was $100 \cdot 0$, somewhat higher than that normally expected for an occupational cohort. The healthy worker effect (about $20 \%$ deficit in overall mortality) usually seen in occupational groups was not present in this cohort, partly because of the absence of pre-employment examinations and the transient nature of the workforce. ${ }^{16}$ The high percentage lost to follow up may have contributed to this finding. As SSA did not have a death record for workers in this group, most likely they were still alive, and the overall SMR presented in this report would be overstated. ${ }^{17}$ Another contributing factor might be that many of the cohort members were transients who were associated with unfavourable mortality experience. Analysis by duration of employment (table 2) supported this explanation; those with employment of less than one year experienced a significantly increased overall SMR of $128 \cdot 6$, whereas those with employment of five years or more had a deficit in overall mortality $($ SMR = 74.9).

For the entire cohort, mortality from respiratory cancer was slightly, but not significantly raised. For cancer of the larynx, the SMR among the men was 360.2 (four observed deaths), approaching the 0.05 percent significance level. Among the women, the SMR for lung cancer was 204.0 (five observed deaths). This did not reach statistical significance.

When mortality from respiratory cancer was examined by duration of employment, no trend was detected. Close to half of the cohort worked for less than two years, however, and more than three quarters of the cohort worked less than five years. Thus most of the cohort worked for only a short period, and analysis by duration of employment $(<1$, $1-2,2-5$, and $>5$ years) for respiratory cancer might not be informative).

For cancer of the larynx, statistically significant excess was seen for the group with higher maximum TWA (SMR = 730.5), and for the group with higher average TWA $(S M R=941 \cdot 1)$. Both SMRs were based on only three deaths, however, and caution must be exercised in interpreting these figures. Also two of these cases worked for less than one year and the other worked for 17 months at their plants. There was no difference detected when mortality from cancer of the larynx was examined by type of process.

For lung cancer, the groups with less exposure (characterised by either low exposure potential, lower maximum TWA, or lower average TWA) appeared to experience higher SMRs than the groups with higher exposure. No reason is offered for this finding. A twofold difference in mortality from lung cancer was seen between the plants with only cold processes $(S M R=64 \cdot 2)$ and those with only hot processes $(S M R=172.1, p<0.05)$. This finding was not consistent with the concept that greater exposure to styrene might cause a higher risk of respiratory cancer, as potential exposure to styrene from cold processes is generally higher than from hot processes.

To investigate further the problem of respiratory cancer, a nested case-control study was conducted. 
The case-control study did not show any significant association between respiratory cancer and direct exposure to styrene, duration of styrene exposure, the type of process (hot $v$ cold), or whether a resin was used. Smoking was the only factor found to be significantly associated with respiratory cancer. No significant interaction existed between the factors examined.

In the entire cohort, only nine deaths were due to lymphatic and haematopoietic cancer, compared with 12.28 expected. For leukaemia five deaths were observed and 4.76 were expected. The cohort as a whole did not experience any excess in either lymphopoietic cancers in general, or leukaemia in particular. Analysis by duration of employment or latency did not show any trend.

When mortality from leukaemia was analysed by departmental exposure, those in departments with high exposure potential experienced an SMR twice that in departments with low exposure potential $(199.3 v 99.9)$. Similar differences were also seen when mortality from leukaemia was analysed by maximum TWA and average TWA, but none of the differences was statistically significant. On the other hand mortality from leukaemia was identical for plants with either hot or cold processes.

Because of the small number of deaths from lymphatic and haematopoietic cancer or from leukaemia, no definite statement regarding this category of disease could be made. The study did, however, rule out any risk greater than 2.3 fold (an SMR of 230 ) in lymphopoietic cancer or 3.4 fold (an SMR of 340 ) in leukaemia for the entire cohort (at alpha of 0.05 and $80 \%$ power). Because of the small number of deaths, no case control analysis was feasible.

It should be pointed out that there were several limitations in this study. Both the per cent lost to follow up and the proportion of outstanding death certificates were higher than we desired, and it was possible that deaths from certain causes were underreported. The cohort was relatively young and the follow up period was short. The numbers of observed deaths from several causes were small, and the corresponding statistical power was limited. Some of these problems can be remedied by extending the observation period in the future. Duration of employment was short for the cohort as a whole, and historical exposure data were very limited. Information on exposure based on records of employment might not be specific. Furthermore, due to the transient nature of the cohort, the members might have been exposed to a variety of different substances and different employment environments. The cohort assembled in this study, however, represents one of the best data sets available to the reinforced plastics and composites industry; many of the limitations mentioned above were not unique to this study, but common to all other occupational epidemiological studies. Given the limitations discussed, no significant cause specific mortality excess for the cohort as a whole was found. The excess in respiratory cancer seen in several subgroups could be explained by differences in smoking habits. Exposure to styrene, as well as to other chemicals used in the reinforced plastics and composites industry, did not increase the risk of respiratory cancer. The data set was too small to offer any definitive conclusion on a modest increase (SMR 200) in risk for leukaemia although it suggested that groups with higher exposure to styrene experienced a higher SMR for leukaemia than the groups with lower exposure. On the other hand, the study ruled out with reasonable statistical power (alpha $=0.05$, power $=80 \%$ ) any rise in mortality from leukaemia greater than 3.4 fold for the cohort as a whole.

1 Nicholson WJ, Selikoff IJ, Seldman H. Mortality experience of styrene polystrene polymerization workers-initial findings. Scand J Work Environ Health 1978;4 (supp 2):247-52.

2 Ott MG, Kolesar RC, Scharweber HC, Schneider EJ, Venable JR. A mortality survey of employees engaged in the development of manufacture of styrene based products. J Occup Med 1980;22:445-60.

3 Meinhardt TJ, Lemen RA, Crandall MS, Young RJ. Environmental epidemiologic investigation of the styrene butadiene rubber industry. Scand J Work Environ Health 1982;8:250-9.

4 Hodgson JT, Jones RD. Mortality of styrene production polymerization and processing workers at a site in northwest England. Scand J Work Environ Health 1985;11:347-52.

5 Downs TD, Crame MM, Kim KW. Mortality among workers at a butadiene facility. Am J Ind Med 1987;12:311-29.

6 Frentzel-Beyme R, Thiess AM, Wieland R. Survey of mortality among employees engaged in the manufacture of styrene and polystyrene at the BASF Ludwigshafen works. Scand JWork Environ Health 1978;4 (supp 2):231-9.

7 Okun AH, Beaumont JJ, Meinhardt TJ, et al. Mortality patterns among styrene exposed boatbuilders. Am J Ind Med 1985;8:193-205.

8 Coggon D, Osmond C, Pannett B, et al. Mortality of workers exposed to styrene in the manufacture of glass reinforced plastics. Scand J Work Environ Health 1987;13:94-9.

9 Matanoski GM, Schwartz L. Mortality of workers in styrene butadiene polymer production. J Occup Med 1987;29:675-80.

10 Arthur D Little Inc. Draft final report: industrial hygiene evaluation of retrospective mortality study plants. 1981 Submitted to Society of the Plastics industry.

11 March GM, Preininger M. OCMAP: A User oriented occupational cohort mortality analysis program. American Statistician 1980;34:254.

12 Mantel N, Haenszel W. Statistical aspects of the analysis of data from retrospective studies of disease. J Natl Cancer Inst 1959;22:719-48.

13 Mantel N. Chi square tests with one degree of freedom: extensions of the Mantel-Haenszel procedure. Journal of the American Statistical Association 1963;58:690-700.

14 Prentice R. Use of the logistic model in retrospective studies. Biometrics 1976;32:599-606.

15 Prentice R, Pyke R. Logistic disease incidence models and case control studies. Biometrika 1976;66:403-11.

16 Fox AJ, Collier PF. Low mortality rates in industrial cohort studies due to selection for work and survival in the industry. British Journal of Preventive and Social Medicine 1976;30: 225-9.

17 Johnson ES. Treatment of subjects lost to follow up in the analysis of mortality studies. J Occup Med 1988;30:60-2.

Accepted 11 June 1990 